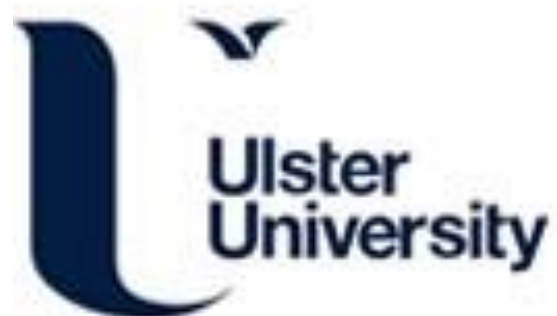

\section{Rhamnolipid and surfactin production from olive oil mill waste as sole carbon source}

Ramírez, I. M., Tsaousi, K., Rudden, M., Marchant, R., Alameda, E. J., Román, M. G., \& Banat, I. (2015).

Rhamnolipid and surfactin production from olive oil mill waste as sole carbon source. Bioresource Technology, 198, 231-236. https://doi.org/10.1016/j.biortech.2015.09.012

Link to publication record in Ulster University Research Portal

\author{
Published in: \\ Bioresource Technology
}

Publication Status:

Published (in print/issue): 01/10/2015

DOI:

10.1016/j.biortech.2015.09.012

\section{Document Version}

Publisher's PDF, also known as Version of record

\section{General rights}

Copyright for the publications made accessible via Ulster University's Research Portal is retained by the author(s) and / or other copyright owners and it is a condition of accessing these publications that users recognise and abide by the legal requirements associated with these rights.

\section{Take down policy}

The Research Portal is Ulster University's institutional repository that provides access to Ulster's research outputs. Every effort has been made to ensure that content in the Research Portal does not infringe any person's rights, or applicable UK laws. If you discover content in the Research Portal that you believe breaches copyright or violates any law, please contact pure-support@ulster.ac.uk. 


\title{
Rhamnolipid and surfactin production from olive oil mill waste as sole carbon source
}

\author{
Ignacio Moya Ramírez ${ }^{\mathrm{a}}$, Konstantina Tsaousi ${ }^{\mathrm{b}}$, Michelle Rudden ${ }^{\mathrm{b}}$, Roger Marchant ${ }^{\mathrm{b}}$, \\ Encarnación Jurado Alameda a , Miguel García Román ${ }^{a}$, Ibrahim M. Banat ${ }^{\text {b,* }}$ \\ ${ }^{a}$ Chemical Engineering Department, Faculty of Sciences, University of Granada, Spain \\ ${ }^{\mathrm{b}}$ School of Biomedical Sciences, University of Ulster, Coleraine BT52 1SA, N. Ireland, UK
}

\section{H I G H L I G H T S}

- Olive mill waste constitutes a difficult by-product to dispose or reuse.

- Olive mill waste can have added value as a substrate for biosurfactant production.

- P. aeruginosa and B. subtilis can utilise olive mill waste as sole carbon source.

- The process achieves recycling of agricultural waste into high added value products.

\section{A R T I C L E I N F O}

\section{Article history:}

Received 21 July 2015

Received in revised form 1 September 2015

Accepted 2 September 2015

Available online 11 September 2015

\section{Keywords:}

Biosurfactants

Alperujo

Surfactin

Rhamnolipids

Olive mill waste

\begin{abstract}
A B S T R A C T
Olive mill waste (OMW) creates a major environmental problem due to the difficulty of further waste processing. In this work we present an approach to give OMW added value by using it for the production of biosurfactants. Two bacterial species, Pseudomonas aeruginosa and Bacillus subtilis, were grown with OMW as the sole carbon source. Glycerol and waste frying oil were used as comparative carbon sources. B. subtilis produced surfactin (a lipopeptide) at a maximum concentration of $3.12 \mathrm{mg} / \mathrm{L}$ with $2 \% \mathrm{w} / \mathrm{v}$ of OMW in the medium, dropping to $0.57 \mathrm{mg} / \mathrm{L}$ with $10 \% \mathrm{w} / \mathrm{v}$ of OMW. In contrast, $P$. aeruginosa produced $8.78 \mathrm{mg} / \mathrm{L}$ of rhamnolipid with $2 \% \mathrm{w} / \mathrm{v}$ OMW increasing to $191.46 \mathrm{mg} / \mathrm{L}$ with $10 \% \mathrm{w} / \mathrm{v}$ OMW. The use of solvent-extracted OMW reduced the biosurfactant production by $70.8 \%$ and $88.3 \%$ for $B$. subtilis and $P$. aeruginosa respectively. These results confirm that OMW is a potential substrate for biosurfactant production.
\end{abstract}

(c) 2015 Elsevier Ltd. All rights reserved.

\section{Introduction}

Biosurfactants (BS) are surface active molecules produced mainly through fermentation employing microorganisms. Biosurfactants can be classified according to their chemical structure into glycolipids, lipopeptides, fatty acids, phospholipids, neutral lipids and polymeric BS (Pacwa-Płociniczak et al., 2011). These compounds have the same properties as their synthetic counterparts i.e., emulsification, detergency, wetting, foaming, etc. (Rosen and Kunjappu, 2012). Furthermore, BS are usually more biocompatible and biodegradable than the synthetic ones due to the fact that they are produced by a biological process using renewable resources,

Abbreviations: BS, biosurfactant; WO, waste cooking oil; OMW, olive oil mill waste; OF-OMW, oil-free olive oil mill waste; DW, dry weight; ST, surface tension.

* Corresponding author.

E-mail address: im.banat@ulster.ac.uk (I.M. Banat). avoiding chemical synthesis (Banat et al., 2010). Additionally, they have important surfactant characteristics like stability at extreme $\mathrm{pH}$, salinity and temperature conditions (Lotfabad et al., 2009). For this reason BS are a real alternative to surfactants produced through chemical processes, and are already being used as replacements for them (Marchant and Banat, 2012a), in addition they can be employed in completely new applications like soil remediation, recovery of heavy metals, food or medicine (Banat et al., 2014a; Campos et al., 2013; Díaz De Rienzo et al., 2014; Gudiña et al., 2013).

The main challenge for BS to become a real option in industry is the production costs. Biosynthesis and downstream steps are still expensive, and cheaper and more efficient production methods need to be developed (Marchant and Banat, 2012b). Although fermentation substrates form only a small part of the total production costs some industrial and agroindustrial by-products and wastes could play an important role since their use would provide added 
value for these wastes that otherwise would be simply discarded, causing a harmful impact on the environment (Henkel et al., 2012; Makkar et al., 2011).

There are a number of different waste products like fatty acids, waste oils or soap stock, which may be used in BS production (Banat et al., 2014b). For example, glycerol is the main coproduct from biodiesel production and has low value due to the presence of impurities. De Sousa et al. (2011) used this waste in the production of rhamnolipids with a yield of $1.9 \mathrm{~g} / \mathrm{L}$. Soap stock, produced during oil refinery and mainly composed of fatty acids, is another suitable industrial waste for BS production (Helmy et al., 2011). For example, Nitschke et al. (2005) obtained $11.7 \mathrm{~g} / \mathrm{L}$ of rhamnolipids using soybean soap stock. Vedaraman and Venkatesh (2011) obtained surfactin with a Bacillus subtilis strain using waste frying oils (sunflower and rice bran) with a yield up to $650 \mathrm{mg} / \mathrm{L}$ of crude extract. Finally other authors proposed the use of residual glycerol and okara (soy pulp) as carbon source in the production of lipopeptides (Slivinski et al., 2012; Sousa et al., 2012). It is necessary to sound a note of caution when considering claims for yields of BS from any oily substrate since the methods of quantification commonly used are extremely unreliable (Marchant and Banat, 2014). Rudden et al. (2015) have recently provided the first fully validated UPLC-MS/MS method for the quantification of the range of rhamnolipid congeners produced by Pseudomonas aeruginosa and have shown that other methods often give significant overestimations of yield.

This paper deals with "alperujo" or olive oil mill waste (OMW), an agroindustrial waste very common in the Mediterranean area, produced after extraction of olive oil. Nowadays, the most frequently used extraction method for olive oil is the two-stageprocess, which yields olive oil and the solid waste, "alperujo." Alperujo is a paste with a high content of lignocellulosic material together with salts and residual oil (Dermeche et al., 2013; Tortosa et al., 2012). Furthermore, this waste is also rich in phenols and polyphenols, substances with phytotoxic and microbial inhibitory properties (McNamara et al., 2008), which can hinder its further processing or recycling. At the present time, alperujo is being re-used in composting, animal feed, or it is simply burned (Tortosa et al., 2012; Vitolo et al., 1999). However, since OMW contains residual oil not extracted in the primary processing, it is worth considering its use in the production of BS, an approach which has hardly been explored, with the exception of Mercadé et al. (1993), who produced rhamnolipids using the liquid fraction of a three stage olive oil extraction as sole carbon source, and our first work (Maass et al., 2015), where we explored the possible production of surfactin from OMW.

Therefore, the objective of our work is to explore the suitability of using OMW as a sole carbon source in the production of two biosurfactants: surfactin and rhamnolipid. For this purpose we used batch fermentations of two bacterial species: B. subtilis and $P$. aeruginosa. We have examined the major parameters that can be optimized to achieve an efficient production process, such as OMW concentration, OMW oil content and kinetics. Two additional carbon sources, i.e. waste cooking oil and glycerol, have been used for comparative purposes.

\section{Methods}

\subsection{Chemicals}

Salts for culture media were purchased from BHD (England). Culture medium salts, nutrient agar, protease peptone and glucose were purchased from Oxoid (England). Glycerol, ethyl acetate, methanol, chloroform, hexane and rhamnolipid and surfactin standards for UPLC-MS analysis were purchased from Sigma
(Germany). Waste oil (WO) was generously provided by two local restaurants in Granada (Spain). OMW was kindly provided by Cooperativa LA UNIÓN (Montilla, Spain). Its composition was as follows: dry matter $35.6 \%$, lipids $3.9 \%$, protein $7.1 \%$, free sugars 9.5\%, Elemental analysis Carbon $48.2 \%$, Nitrogen $1.2 \%$, Hydrogen 7.1\% which is similar to that reported by Niaounakis and Halvadakis (2006).

\subsection{Microorganisms}

The identities of the microorganisms used were confirmed as $B$. subtilis N1 (through sequencing the 16S rRNA gene, GenBank accession number KT595698) and P. aeruginosa PAO1 held in the University of Ulster collection.

\subsection{Culture conditions}

The bacteria were first inoculated onto nutrient-agar and incubated at $37^{\circ} \mathrm{C}$ for $24 \mathrm{~h}$. Two seed cultures were prepared before starting the batch culture. Seed culture 1 was a PPGAS medium with Tris- $\mathrm{HCl}(19 \mathrm{~g} / \mathrm{L})$, protease peptone $(10 \mathrm{~g} / \mathrm{L})$, glucose $(5 \mathrm{~g} / \mathrm{L})$, $\mathrm{KCl}(1.5 \mathrm{~g} / \mathrm{L}), \mathrm{NH}_{4} \mathrm{Cl}(1 \mathrm{~g} / \mathrm{L})$ and $\mathrm{MgSO}_{4}(0.4 \mathrm{~g} / \mathrm{L})$ in distilled water. Twenty $\mathrm{ml}$ of this medium was inoculated with cells from the plate culture and maintained at $37^{\circ} \mathrm{C}$ for $24 \mathrm{~h}$ at $160 \mathrm{rpm}$. Seed culture 2 was a mineral salt medium (MSM) composed of glucose $(20 \mathrm{~g} / \mathrm{L})$, $\mathrm{NaNO}_{3}(2 \mathrm{~g} / \mathrm{L}), \mathrm{Na}_{2} \mathrm{HPO}_{4}(0.9 \mathrm{~g} / \mathrm{L}), \mathrm{KH}_{2} \mathrm{PO}_{4}(0.7 \mathrm{~g} / \mathrm{L}), \mathrm{MgSO}_{4} \cdot 7 \mathrm{H}_{2} \mathrm{O}$ $(0.4 \mathrm{~g} / \mathrm{L}), \mathrm{CaCl}_{2} \cdot 2 \mathrm{H}_{2} \mathrm{O}(0.1 \mathrm{~g} / \mathrm{L}), \mathrm{FeSO}_{4} \cdot 7 \mathrm{H}_{2} \mathrm{O}(0.001 \mathrm{~g} / \mathrm{L})$ and the following trace elements $\mathrm{ZnSO}_{4} \cdot 7 \mathrm{H}_{2} \mathrm{O}(0.7 \mathrm{mg} / \mathrm{L}), \quad \mathrm{CuSO}_{4} \cdot 5 \mathrm{H}_{2} \mathrm{O}$ $(0.5 \mathrm{mg} / \mathrm{L}), \quad \mathrm{MnSO}_{4} \cdot \mathrm{H}_{2} \mathrm{O} \quad(0.5 \mathrm{mg} / \mathrm{L}), \quad \mathrm{H}_{3} \mathrm{BO}_{3} \quad(0.26 \mathrm{mg} / \mathrm{L})$ and $\mathrm{Na}_{2} \mathrm{MoO}_{4} \cdot 2 \mathrm{H}_{2} \mathrm{O}(0.06 \mathrm{mg} / \mathrm{L})$. Seed culture 2 was inoculated with $5 \% \mathrm{v} / \mathrm{v}$ of seed culture 1 , and was grown again at $37^{\circ} \mathrm{C}$ and $160 \mathrm{rpm}$ for $24 \mathrm{~h}$, for adaptation of cells in MSM.

For the batch fermentation experiments, $100 \mathrm{~mL}$ of medium containing the selected concentration of carbon source $(2 \%, 5 \%$ or $10 \% \mathrm{w} / \mathrm{v}$ ) was added to a $1 \mathrm{~L}$ Erlenmeyer flask. The medium was the MSM (see above for seed culture 2) without glucose. Glycerol, WO and/or OMW were also tested as carbon sources. Cultures were inoculated with $5 \% \mathrm{v} / \mathrm{v}$ of seed culture 2 and maintained at $37^{\circ} \mathrm{C}$ and $160 \mathrm{rpm}$. All experiments were carried out in triplicate.

\subsection{Analytical assays}

For OMW characterization, evaporation at $105{ }^{\circ} \mathrm{C}$ to constant weight was used to determine the moisture content and the Kjeldahl method (ASTM E258) for total nitrogen. Extraction of the residual oil fraction in OMW was carried out with hexane. The ratio waste/solvent was $1 / 5(\mathrm{w} / \mathrm{v})$, and the process was repeated three times. Afterwards oil free OMW was dried, and finally the moisture content was reset again to the initial value.

\subsection{Culture media processing and measurements}

Cell growth was measured by dry weight (DW) of pellets obtained from $1 \mathrm{~mL}$ of culture, centrifuged at $10^{5} \mathrm{~g}$ for $15 \mathrm{~min}$ and dried at $80^{\circ} \mathrm{C}$ to constant weight (Maass et al., 2015). These measurements were carried out in triplicate for each sample, but the results obtained were quite variable due to contamination with the solid fraction of OMW, and therefore they were only used as general indicators of biomass production.

The culture medium was centrifuged at $10^{5} \mathrm{~g}$ and $4{ }^{\circ} \mathrm{C}$ for $15 \mathrm{~min}$ and the supernatant was carefully collected. Surface tension (ST) of the clarified medium was measured using the Wilhelmy method in a Kruss K 10 ST tensiometer (Hamburg, Germany). Afterwards BS (rhamnolipids or surfactins) were extracted. For this purpose $50 \mathrm{~mL}$ of supernatant was gently mixed with the same volume of ethyl acetate. Organic and aqueous 
phases were separated in a funnel. These two last steps were repeated three times. The three organic fractions obtained were combined and rotary evaporated. The crude extract was dissolved in a small amount of methanol in order to be transferred to a preweighted vial, then dried and weighed to give the yield of crude extract.

\subsection{Surfactant quantification}

The BS produced was identified and quantified by UPLC-MS. The measurements were conducted in an UPLC Waters Acquity H-Class chromatograph (Waters Corporation, Milford-MA, USA) equipped with a Waters UPLC BEH C-18 column and coupled to a mass spectrometer (Waters Xevo-TG-S). For surfactin analysis the mobile phase consisted of a mixture of $20 \%(\mathrm{v} / \mathrm{v})$ of water and $80 \%(\mathrm{v} / \mathrm{v})$ of acetonitrile, both with a $0.1 \% \mathrm{w} / \mathrm{w}$ of formic acid. The volumetric flow rate of the mobile phase and the sample injection volume were $0.5 \mathrm{~mL} / \mathrm{min}$ and $3.0 \mu \mathrm{L}$, respectively. Mass spectrometry was conducted in positive mode (ES+), under the following conditions: capillary voltage $3 \mathrm{kV}$, ion source temperature $150{ }^{\circ} \mathrm{C}$, desolvation temperature $500^{\circ} \mathrm{C}$, and desolvation gas flow rate $800 \mathrm{~L} / \mathrm{h}$. For rhamnolipids analysis the mobile phases was $70 \%(\mathrm{v} / \mathrm{v})$ water and $30 \%(\mathrm{v} / \mathrm{v})$ acetonitrile and the mass spectrometry was carried out in negative mode (ES-), all the other conditions were as described above.

\section{Results and discussion}

\subsection{The effect of carbon source}

Initially, the effect of the carbon source on the cell dry weight (DW), surface tension (ST) of the supernatant and BS concentration after 7 days of culture was determined.

Both the type of carbon source and its concentration affected the DW and ST of the cultures. With the exception of $2 \% \mathrm{w} / \mathrm{v}$ $P$. aeruginosa glycerol yielded the highest values of DW (Fig. 1). The DW values for waste oil and OMW were lower, and similar for these two carbon sources. Higher concentrations of carbon source yielded higher values of DW in all cases, although the increase with concentration was higher for the glycerol cultures. However, in the case of $B$. subtilis the DW increased with the concentration of glycerol and OMW, while waste oil as carbon source yielded less biomass (Fig. 1). Remarkably, the values of DW obtained for glycerol and OMW when using Bacillus were very similar at concentrations of 5 and $10 \% \mathrm{w} / \mathrm{v}$.
In the case of ST, the lowest values were achieved in the cultures with glycerol for both microorganisms, slightly decreasing with increasing substrate concentration for $P$. aeruginosa and the reverse for $B$. subtilis, and ranging between 29.2 and $33.4 \mathrm{mN} / \mathrm{m}$. The same effect was observed for WO as carbon source. Of special interest is that for OMW, ST decreased with concentration from 45.1 to $33.7 \mathrm{mN} / \mathrm{m}$ in Pseudomonas cultures, whereas an increase from 39.3 to $46.6 \mathrm{mN} / \mathrm{m}$ was obtained with Bacillus.

These results suggest that both microorganisms are able to grow in OMW and produce molecules with interfacial properties. $P$. aeruginosa seems better able to grow and produce surfactant with OMW in the medium, especially at higher OMW concentrations. The increase in final ST with OMW concentration in B. subtilis cultures suggests that this waste inhibits the ability of this microorganism to produce substances with interfacial activity (Fig. 1). This effect could be due to the antimicrobial activity of phenols found in OMW, which is well known and described in the literature (Obied et al., 2005; Perez et al., 1992). For instance, Moreno et al. (1990) reported that this antimicrobial effect is higher for Gram-positive than for Gram-negative bacteria. Therefore, Gram-negative species, such as $P$. aeruginosa, could be more suitable to grow on OMW as carbon source.

UPLC-MS analysis of the extracts from the culture media confirmed that $P$. aeruginosa had produced rhamnolipids and B. subtilis surfactins. This result supports the contention that it is feasible to produce BS from OMW.

Furthermore, the direct quantification of the produced BS confirmed that the highest BS amount was produced with glycerol for both species (see Table 1), while WO and OMW yielded less BS. With regard to the effect of the carbon source concentration, the amount of rhamnolipid produced remained relatively constant with increasing glycerol concentration, while surfactin decreased almost to a half as the glycerol concentration was increased from $2 \%$ to $10 \% \mathrm{w} / \mathrm{v}$. Additionally, both strains yielded less BS with increasing WO concentration, with the reduction in surfactin more marked. Under the best conditions using OMW in these experiments $191.46 \mathrm{mg} / \mathrm{L}$ of rhamnolipids and $3.12 \mathrm{mg} / \mathrm{L}$ of surfactin were obtained, these conditions corresponded to $10 \%$ and $2 \% \mathrm{w} / \mathrm{v}$ of OMW for $P$. aeruginosa and $B$. subtilis respectively. Again it is interesting to note the effect of OMW concentration in both strains: while $P$. aeruginosa grew better with OMW as carbon source, increasing its productivity at higher concentration, B. subtilis had reduced production of surfactin as the concentration of OMW was increased from $2 \%$ to $10 \% \mathrm{w} / \mathrm{v}$. Furthermore, in terms of efficiency, rhamnolipid $\mathrm{Y}_{\mathrm{P} / \mathrm{S}}$ was considerably higher than
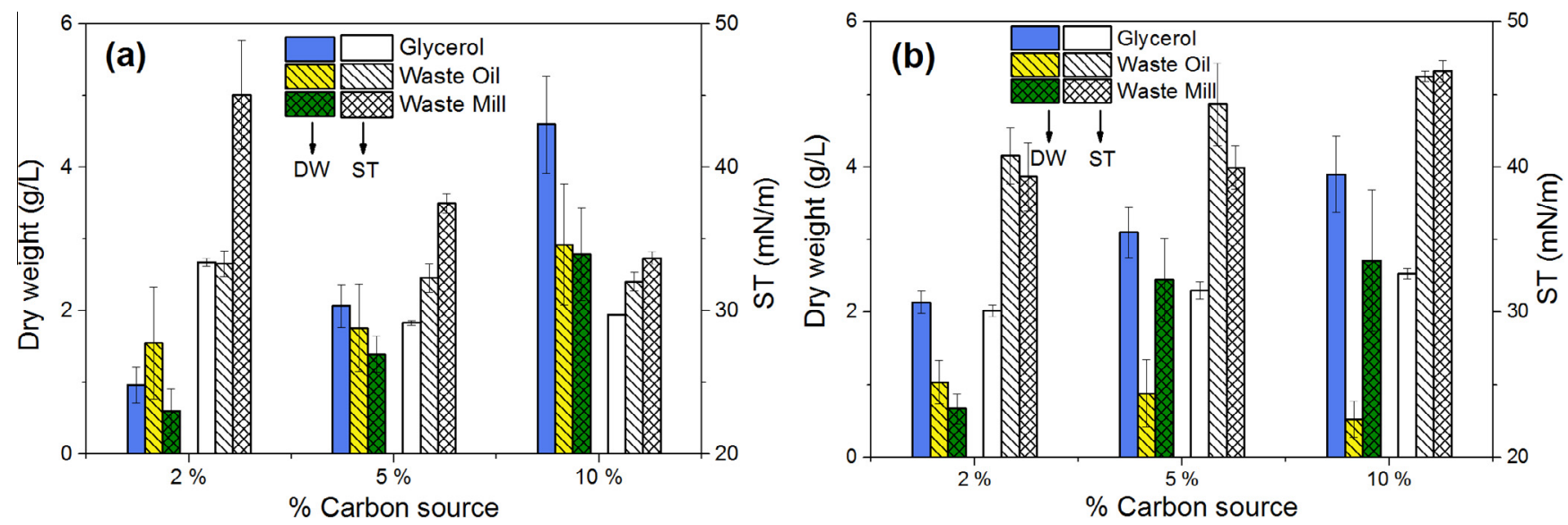

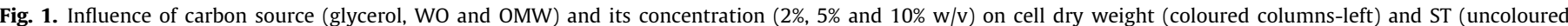

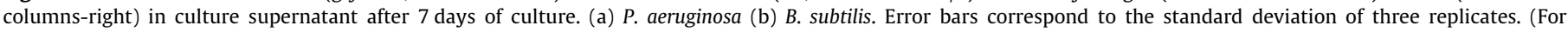
interpretation of the references to colour in this figure legend, the reader is referred to the web version of this article.) 
Table 1

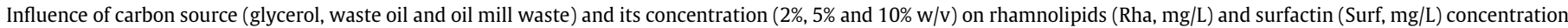
in the culture medium for $P$. aeruginosa and B. subtilis cultures.

\begin{tabular}{|c|c|c|c|c|c|c|}
\hline & \multicolumn{2}{|l|}{ Glycerol } & \multicolumn{2}{|l|}{ WO } & \multicolumn{2}{|l|}{ OMW } \\
\hline & Rha $(\mathrm{mg} / \mathrm{L})$ & Surf (mg/L) & Rha (mg/L) & $\overline{\text { Surf }(\mathrm{mg} / \mathrm{L})}$ & Rha (mg/L) & $\overline{\text { Surf }(\mathrm{mg} / \mathrm{L})}$ \\
\hline $2 \%$ & $1564.70 \pm 106.70$ & $21.72 \pm 2.61$ & $899.94 \pm 74.04$ & $1.01 \pm 0.15$ & $8.78 \pm 0.49$ & $3.12 \pm 0.13$ \\
\hline $5 \%$ & $1295.05 \pm 82.62$ & $20.76 \pm 2.49$ & $496.23 \pm 139.23$ & $0.08 \pm 0.02$ & $27.07 \pm 1.71$ & $0.93 \pm 0.21$ \\
\hline $10 \%$ & $1906.83 \pm 121.66$ & $13.51 \pm 1.63$ & $315.59 \pm 8.87$ & n.d. & $191.46 \pm 18.76$ & $0.57 \pm 0.10$ \\
\hline
\end{tabular}

n.d. = not detected.

surfactin at their respective optimum condition for OMW as carbon source: $19.15 \mathrm{mg}$ rhamnolipids/g OMW at $10 \% \mathrm{w} / \mathrm{v}$ OMW versus $1.56 \mathrm{mg}$ surfactin/g OMW at $2 \% \mathrm{w} / \mathrm{v}$ OMW.

The higher BS yields obtained with OMW for rhamnolipid and surfactin were respectively $12 \%$ and $4 \%$ of the obtained yield with glycerol at $2 \% \mathrm{w} / \mathrm{v}$. In spite of this, OMW would be a suitable raw material in the BS production process due to its low cost. Although carbon substrate cost is not a critical element in the overall production costs of BS the opportunity to add considerable value to the OMW is potentially important. The OMW used in these experiments contained little residual oil, however, if OMW was used prior to any secondary extraction of oil using solvents the levels of BS could be increased thereby improving the economics of downstream processing. An additional advantage of using OMW is the purity of the extract, which has intermediate values between glycerol and WO. Actually, the experiments carried out with WO presented the lowest purity; particularly for B. subtilis cultures (see Table 2). In these cultures unconsumed oil is quite difficult to separate from the rest of the medium, while when using OMW, this problem does not exist, because solid particles are easily separated. This is a clear advantage of OMW over WO for industrial BS production, because it will simplify downstream processing, which is a major factor to take into account, in addition to the price of raw materials (Smyth et al., 2010).

\subsection{Kinetics}

Once it had been demonstrated that it is possible to produce BS with OMW as sole carbon source the next steps were oriented towards process optimisation. With this aim, a kinetic study was carried out to examine the course of BS production during the culture using this waste as sole carbon source. DW and BS concentration were measured at different times. Both parameters increased rapidly in the exponential growth phase, and remained almost constant in the log phase for both microorganisms. Fig. 2 shows how biomass concentration in the culture medium reaches a maximum after 6 days for $P$. aeruginosa and 4 days for B. subtilis. In the case of BS maximum concentrations were reached after 8 days for $P$. aeruginosa and 6 days for $B$. subtilis. The production of surfactin by $B$. subtilis appears to be closely associated with the growth of the organism since surfactin is detected in the medium very early. In contrast rhamnolipid production by $P$. aeruginosa follows the

\section{Table 2}

Purity (in\%) of rhamnolipids (Rha) and surfactin (Surf) in crude extracts from culture medium, at three different concentration of glycerol, waste oil (WO) and olive oil mill waste (OMW)

\begin{tabular}{|c|c|c|c|c|c|c|}
\hline \multirow[b]{2}{*}{ Concentration } & \multicolumn{2}{|c|}{ Glycerol } & \multicolumn{2}{|l|}{ WO } & \multicolumn{2}{|l|}{ OMW } \\
\hline & Rha & Surf & Rha & Surf & Rha & Surf \\
\hline $2 \%$ & 69.09 & 6.38 & 20.23 & 0.05 & 6.62 & 1.24 \\
\hline $5 \%$ & 57.97 & 1.06 & 10.52 & 0.01 & 6.86 & 0.13 \\
\hline $10 \%$ & 62.93 & 0.52 & 5.11 & n.d. & 20.43 & 0.05 \\
\hline
\end{tabular}

n.d. = not detected.

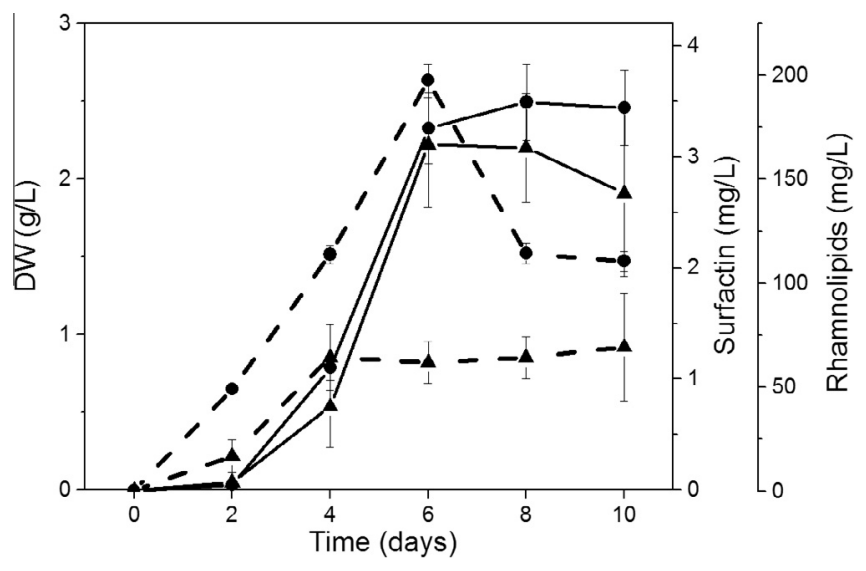

Fig. 2. Time course of DW $(\boldsymbol{\Delta})$ and BS $(\bullet)$ production for $P$. aeruginosa (continuous line) and $B$. subtilis (broken line) cultures. OMW was the sole carbon source at concentrations of $10 \% \mathrm{w} / \mathrm{v}$ for Pseudomonas and $2 \% \mathrm{w} / \mathrm{v}$ for Bacillus.

pattern described by other workers where production takes place as the cells enter stationary phase (Perfumo et al., 2013).

In order to gain knowledge of the BS produced with OMW, we studied the different congeners produced by using UPLC/MS. Table 3 presents the different congeners detected and their average relative abundance, which remained almost constant during the whole kinetic study for both microorganisms. For $P$. aeruginosa the most abundant congener was the dirhamnolipid with 10 carbon in each fatty acid chain (2 Rha-C10-C10). Whereas $B$. subtilis mainly produced surfactins with 14 and 15 carbon atoms in the $\beta$-hydroxy-fatty acid tail.

\subsection{Combined carbon source study; OMW toxicity}

With the purpose of achieving a better understanding of the problems produced by using OMW, we combined it with glycerol as an additional carbon source. Glycerol concentration was kept constant at $2 \% \mathrm{w} / \mathrm{v}$, an amount that was completely consumed after the 7 days of culture (data not shown). OMW was added at $2 \%$ and $10 \% \mathrm{w} / \mathrm{v}$, as shown in Fig. 3.

For both microorganisms combined carbon sources yielded less BS than experiments carried out only with glycerol, and more than when only OMW was used (Fig. 3). Compared with experiments when only glycerol was used, rhamnolipid productivity decreased by $47.6 \%$ and $75.9 \%$ in cultures with $2 \%$ and $10 \% \mathrm{w} / \mathrm{v}$ of OMW respectively. For surfactin the reduction was of $5.6 \%$ and a $92.2 \%$ for the same conditions. This indicates that some component(s) in OMW have an inhibitory effect on the production of BS. Previously we noted the inhibition of surfactin production by B. subtilis at high concentrations of OMW. Additionally these results show how this waste could have hindered the ability of $P$. aeruginosa to produce rhamnolipids, although this effect was not fully obvious when OMW was the sole carbon source. As discussed previously, this reduction could be due to the presence of phenols in OMW. 
Table 3

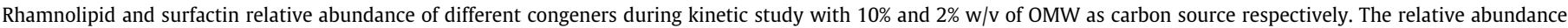
remained almost constant throughout each experiment.

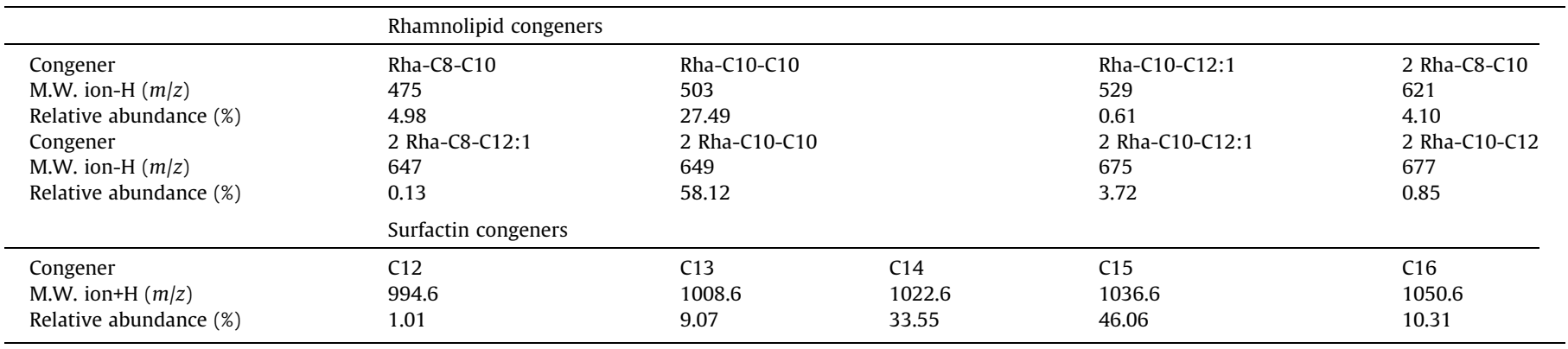

Data are average of duplicate determinations.

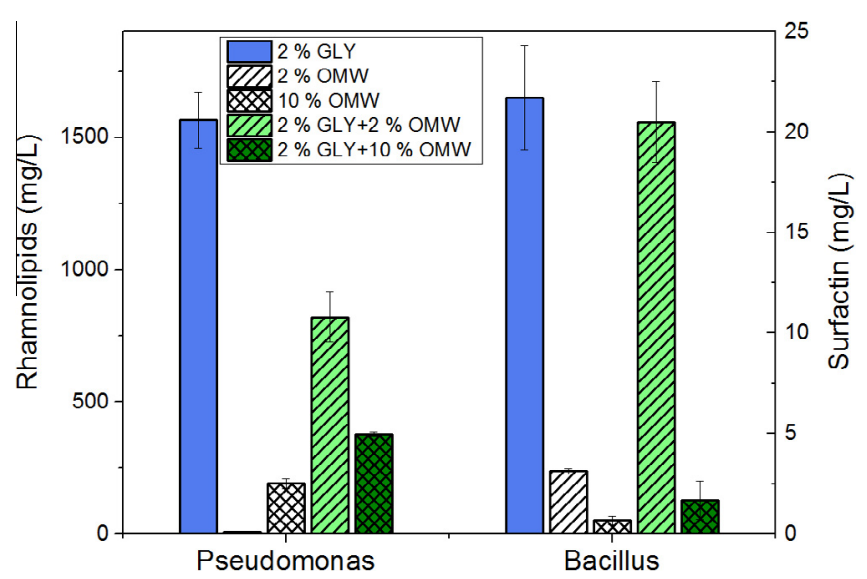

Fig. 3. Production of rhamnolipids and surfactin by $P$. aeruginosa and $B$. subtilis respectively using glycerol, OMW and glycerol mixed with OMW, after 7 days of culture.

Therefore in order to develop an optimal BS production process the use of more phenol-resistant strains or phenol removal should be contemplated.

\subsection{Relevance of residual oil in OMW}

Our first hypothesis when using the waste from olive oil extraction was that bacteria could use the residual oil in this waste
( $1.4 \% \mathrm{w} / \mathrm{w}$ of the wet product) to produce BS, as reported in many studies where waste oil is used as carbon source. With the purpose of confirming if bacteria could process this residual oil, we carried out fermentations with oil-free OMW (OF-OMW).

Fig. 4 shows how for both bacteria the biomass and the BS production were considerably lower with oil-free OMW, which yielded a $88.5 \%$ and $70.7 \%$ less BS, compared to fresh OMW, for $P$. aeruginosa and $B$. subtilis respectively. This confirms the importance of residual oil in the BS production, despite its low concentration in OMW.

Surprisingly, both strains still produced some BS with oil-free OMW without oil. This suggests that there is something else besides oil that bacteria are able to use as carbon source. Probably, hemicellulosic material, and more specifically, free sugars could be an available and easy carbon source to incorporate (Jain et al., 2013; Makkar et al., 2011). However this hypothesis needs further investigation.

\section{Conclusions}

In this study we demonstrate that olive oil mill waste (OMW) is a potential carbon source for biosurfactant production. OMW is somewhat inhibitory to BS production but can be used at appropriate levels. The residual oil in OMW provides a major source of carbon but other nutrients in the waste also contribute. OMW is an abundant by-product in Mediterranean countries which could be used for biosurfactant production achieving two important objectives: (i) recycling of a waste that is difficult to process, and

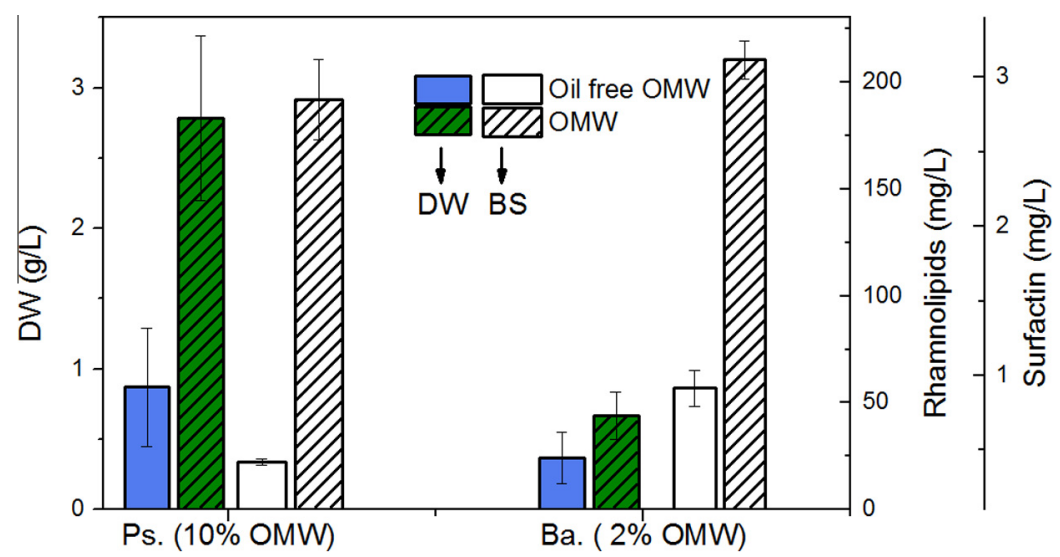

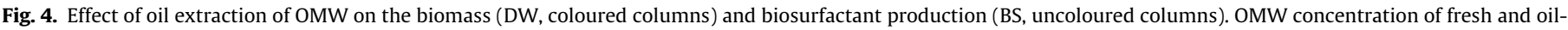
free OMW were fixed as $10 \%$ for $P$. aeruginosa cultures and $2 \%$ for $B$. subtilis. The duration of cultures was 7 days. 
(ii) production of high added value products. However, questions remain before an economically viable process can be developed.

\section{Acknowledgements}

The authors acknowledge the financial support provided by the Andalusian Regional Government (Project P10-TEP-6550). Funding from the European Commission within the FP-7 PROJECT under Grant Agreement No. 312139 "Integrated Biotechnological Solutions for Combating marine Oil Spills" - KILL SPILL is also acknowledged.

\section{References}

Banat, I.M., Franzetti, A., Gandolfi, I., Bestetti, G., Martinotti, M.G., Fracchia, L., Smyth, T.J., Marchant, R., 2010. Microbial biosurfactants production, applications and future potential. Appl. Microbiol. Biotechnol. 87, 427-444.

Banat, I.M., Díaz De Rienzo, M.A., Quinn, G.A., 2014a. Microbial biofilms: biosurfactants as antibiofilm agents. Appl. Microbiol. Biotechnol. 98, 99159929.

Banat, I.M., Satpute, S.K., Cameotra, S.S., Patil, R., Nyayanit, N.V., 2014b. Cost effective technologies and renewable substrates for biosurfactants' production. Front. Microbiol. 5, 1-18.

Campos, J.M., Montenegro Stamford, T.L., Sarubbo, L.A., de Luna, J.M., Rufino, R.D., Banat, I.M., 2013. Microbial biosurfactants as additives for food industries. Biotechnol. Prog. 29, 1097-1108.

De Sousa, J.R., da Costa Correia, J.A., de Almeida, J.G.L., Rodrigues, S., Pessoa, O.D.L., Melo, V.M.M., Gonçalves, L.R.B., 2011. Evaluation of a co-product of biodiesel production as carbon source in the production of biosurfactant by $P$. aeruginosa MSIC02. Process Biochem. 46, 1831-1839.

Dermeche, S., Nadour, M., Larroche, C., Moulti-Mati, F., Michaud, P., 2013. Olive mill wastes: biochemical characterizations and valorization strategies. Process Biochem. 48, 1532-1552.

Díaz De Rienzo, M.A., De Ranson, I.U., Dorta, B., Banat, I.M., Blazquez, M.L., Gonzalez, F., Muñoz, J.A., Ballester, A., 2014. Metal removal from contaminated soils through bioleaching with oxidizing bacteria and rhamnolipid biosurfactants. Soil Sediment. Contamin. 24, 16-29.

Gudiña, E.J., Rangarajan, V., Sen, R., Rodrigues, L.R., 2013. Potential therapeutic applications of biosurfactants. Trends Pharmacol. Sci. 34, 667-675.

Helmy, Q., Kardena, E., Funamizu, N., Wisjnuprapto, 2011. Strategies toward commercial scale of biosurfactant production as potential substitute for it's chemically counterparts. Int. J. Biotechnol. 12, 66-86.

Henkel, M., Müller, M.M., Kügler, J.H., Lovaglio, R.B., Contiero, J., Syldatk, C., Hausmann, R., 2012. Rhamnolipids as biosurfactants from renewable resources: concepts for next-generation rhamnolipid production. Process Biochem. 47, 1207-1219.

Jain, R.M., Mody, K., Joshi, N., Mishra, A., Jha, B., 2013. Effect of unconventional carbon sources on biosurfactant production and its application in bioremediation. Int. J. Biol. Macromol. 62, 52-58.

Lotfabad, T.B., Shourian, M., Roostaazad, R., Najafabadi, A.R., Adelzadeh, M.R., Noghabi, K.A., 2009. An efficient biosurfactant-producing bacterium Pseudomonas aeruginosa MR01, isolated from oil excavation areas in south of Iran. Colloid Surf. B. Biointerf. 69, 183-193.

Maass, D., Moya Ramírez, I., García Román, M., Jurado Alameda, E., Ulson de Souza, A.A., Borges Valle, J.A., Altmajer Vaz, D., 2015. Two-phase olive mill waste (alpeorujo) as carbon source for biosurfactant production. J. Chem. Technol. Biotechnol. http://dx.doi.org/10.1002/jctb.4.
Makkar, R.S., Cameotra, S.S., Banat, I.M., 2011. Advances in utilization of renewable substrates for biosurfactant production. AMB Express 1, 5.

Marchant, R., Banat, I.M., 2012a. Biosurfactants: a sustainable replacement for chemical surfactants? Biotechnol. Lett. 34, 1597-1605.

Marchant, R., Banat, I.M., 2012b. Microbial biosurfactants: challenges and opportunities for future exploitation. Trends Biotechnol. 30, 558-565.

Marchant, R., Banat, I.M., 2014. Protocols for Measuring Biosurfactant Production in Microbial Cultures. In: Srivdhya, D. (Ed.), Springer Protocols Handbooks. Humana Press, pp. 1-10.

McNamara, C.J., Anastasiou, C.C., O'Flaherty, V., Mitchell, R., 2008. Bioremediation of olive mill wastewater. Int. Biodeterior. Biodegradation 61, 127-134.

Mercadé, M.E., Manresa, M.A., Robert, M., Espuny, M.J., de Andrés, C., Guinea, J. 1993. Olive oil mill effluent (OOME). New substrate for biosurfactant production. Bioresour. Technol. 43, 1-6.

Moreno, E., Quevedo, J., Ramos-Cormenzana, A., 1990. Antimicrobial activity of wastewaters from olive oil mills. In: Cheremisoff, P.N. (Ed.), Encyclopedia of Environmental Control Technology. Gulf Publishing Co., Houston, pp. 731-757.

Niaounakis, M., Halvadakis, C.P., 2006. Characterization of Olive Processing Waste. In: Niaounakis, M., Halvadakis, C.P. (Eds.), Olive Processing Waste Management Literature Review and Patent Survey, second ed. Elsevier, UK.

Nitschke, M., Costa, S.G.V.A.O., Haddad, R., Gonçalves, L.A.G., Eberlin, M.N., Contiero, J., 2005. Oil wastes as unconventional substrates for rhamnolipid biosurfactant production by Pseudomonas aeruginosa LBI. Biotechnol. Prog. 21, 1562-1566.

Obied, H.K., Allen, M.S., Bedgood, D.R., Prenzler, P.D., Robards, K., Stockmann, R., 2005. Bioactivity and analysis of biophenols recovered from olive mill waste. J. Agric. Food Chem. 53, 823-837.

Pacwa-Płociniczak, M., Płaza, G.A., Piotrowska-Seget, Z., Cameotra, S.S., 2011 Environmental applications of biosurfactants: recent advances. Int. J. Mol. Sci. 12, 633-654.

Perez, J., Rubia, T.D.E.L.A., Moreno, J., Nez, J.M., 1992. Activity of olive oil waste waters. Environ. Toxicol. Chem. 11, 489-495.

Perfumo, A., Rudden, M., Smyth, T.J.P., Marchant, R., Stevenson, P.S., Parry, N.J., Banat, I.M., 2013. Rhamnolipids are conserved biosurfactants molecules: implications for their biotechnological potential. Appl. Microbiol. Biotechnol. 97, 7297-7306.

Rosen, M.J., Kunjappu, J.T., 2012. Surfactants and Interfacial Phenomena, fourth ed. John Wiley \& Sons, New Jersey.

Rudden, M., Tsaousi, K., Marchant, R., Banat, I.M., Smyth, T.J., 2015. Development and validation of an ultra-performance liquid chromatography tandem mass spectrometry (UPLC-MS/MS) method for the quantitative determination of rhamnolipid congeners. Appl. Microbiol. Biotechnol. http://dx.doi.org/10.1007/ s00253-015-6837-1.

Slivinski, C.T., Mallmann, E., De Araújo, J.M., Mitchell, D.A., Krieger, N., 2012. Production of surfactin by Bacillus pumilus UFPEDA 448 in solid-state fermentation using a medium based on okara with sugarcane bagasse as a bulking agent. Process Biochem. 47, 1848-1855.

Smyth, T.J.P., Perfumo, A., McClean, S., Marchant, R., Banat, I.M., 2010. Isolation and analysis of lipopeptides and high molecular weight biosurfactants. In: Timmis K. (Ed.), Handbook of Hydrocarbon and Lipid Microbiology SE - 290. Springer, Berlin Heidelberg, pp. 3687-3704.

Sousa, M., Melo, V.M.M., Rodrigues, S., Sant'ana, H.B., Goncalves, L.R.B., 2012 Screening of biosurfactant-producing Bacillus strains using glycerol from the biodiesel synthesis as main carbon source. Bioprocess Biosyst. Eng. 35, 897906.

Tortosa, G., Alburquerque, J.A., Ait-Baddi, G., Cegarra, J., 2012. The production of commercial organic amendments and fertilisers by composting of two-phase olive mill waste ("alperujo"). J. Clean. Prod. 26, 48-55.

Vedaraman, N., Venkatesh, N., 2011. Production of surfactin by bacillus subtilis mtcc 2423 from waste frying oils. Braz. J. Chem. Eng. 28, 175-180.

Vitolo, S., Petarca, L., Bresci, B., 1999. Treatment of olive oil industry wastes. Bioresour. Technol. 67, 129-137. 